\title{
Sex Robots in Care
}

\section{Setting the Stage for a Discussion on the Potential Use of Sex Robots for Persons with Disabilities}

\author{
Eduard Fosch-Villaronga ${ }^{\dagger}$ \\ eLaw Center for Law and Digital Technologies \\ Leiden University \\ Leiden, The Netherlands \\ e.fosch.villaronga@law.leidenuniv.nl
}

\author{
Adam Poulsen ${ }^{\dagger}$ \\ School of Computing and Mathematics \\ Charles Sturt University \\ Australia \\ apoulsen@csu.edu.au
}

\begin{abstract}
Although every human should enjoy physical touch, intimacy, and sexual pleasure, persons with disabilities are often not in the position to fully experience the joys of life in the same manner as abled people. The United Nations stated in 1993 that persons with disabilities should enjoy family life and personal integrity and should not be denied the opportunity to experience their sexuality, have sexual relationships, and experience parenthood. However, after nearly 30 years of discussion, universal access to sexual and reproductive health remains an unfinished agenda for the disabled, as if society failed in recognizing people with disabilities as sexual beings. In this respect, a growing body of scholars have started to explore the idea of using technology to help disabled people satisfy some of these needs, although not without controversy. In concrete, ideas surrounding the use of robots for sex care purposes have been put forward, as service robots performing actions contributing directly towards improvement in the satisfaction of a user's sexual needs. This paper continues to explore the potential use of these robots in disability care for sex care purposes, including for those with physical and mental health disabilities, which is currently underexplored. Our contribution seeks to understand whether sex robots could serve as a step forward in realizing the sexual rights of persons with disabilities. By building on a conceptual analysis of how sex robots could empower persons with disabilities to exercise their sexual rights, we hope to inform the policy debate around robots' regulation and governance and set the scene for further research.
\end{abstract}

\section{CCS CONCEPTS}

- Applied computing $\rightarrow$ Law, social and behavioral sciences - Social and professional topics $\rightarrow$ Government Technology Policy and Medical information policy $\bullet$ Human-centered computing $\rightarrow$ Collaborative and social computing.

$\dagger$ Both authors contributed equally to this research.

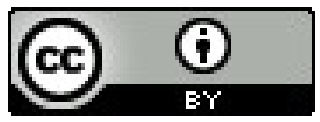

This work is licensed under a Creative Commons Attribution International 4.0 License.

HRI '21 Companion, March 8-11, 2021, Boulder, CO, USA.

(C) 2021 Copyright held by the owner/author(s).

ACM ISBN 978-1-4503-8290-8/21/03.

https://doi.org/10.1145/3434074.3446907

\section{KEYWORDS}

sex robot; care; sexual rights; persons with disabilities; disability care; sex care; ethical legal and societal issues

\section{ACM Reference format:}

Eduard Fosch-Villaronga and Adam Poulsen. 2021. Sex Robots in Care: Setting the Stage for a Discussion on the Potential Use of Sexual Robot Technologies for Persons with Disabilities. In Companion of the 2021 the 2021 ACM/IEEE International Conference on Human-Robot Interaction (HRI '21 Companion), March 8-11, 2021, Boulder, CO, USA. ACM, New York, NY, USA. 9 pages, DOI: https://doi.org/10.1145/3434074.3446907

\section{INTRODUCTION}

The creation and deployment of sex robots are accelerating. Sex robots are service robots that perform actions contributing directly towards improvement in the satisfaction of the sexual needs of a user [26]. Typically, sex robots have different embodiments, including fully or partially-bodied humanoids; body parts such as arms, heads, or genitals used for sex-related tasks; or non-biomimetic robotic devices used for sexual pleasure. These robots usually display realistic sex-related body movements, have sensors to react in real-time to user interaction, and include human cues such as voice, gaze, and lipsync to support human-like human-robot interactions. Other 'artificial agents capable of erotically engaging with humans' or erobots are virtual or augmented reality partners and erotic chatbots [19]. However, this article frames this study exploring a particular intervention in sex care, that of sex robots.

A growing body of literature reflects on other uses of sex robots than satisfying sexual pleasures. These robots may help address first-time sex-related anxiety, treat sexual dysfunctions, or promote safer sex in educational settings. Sex robots could create a safe, non-judgmental environment for people who feel insecure about their sexual orientation [45, 74]. Other more controversial applications are treatments for pedophiles and potential sex offenders [10].

This paper continues to explore new uses for sex robots. We explore the potential use of sex robots for disability care purposes, including the physical and mentally ill, which is currently underexplored. The raison d'être of this article is simple: although every human should enjoy physical touch, intimacy, and sexual pleasure, persons with disabilities are often not in the position to fully experience the joys of life in the same manner as abled people. Moreover, although there have been 
international efforts towards realizing their sexual rights from institutions like the United Nations [94, 95], after nearly 30 years of discussion, this remains an unfinished agenda for the disabled [91]. This article argues that while contemporary societies succeeded in accepting (at the time) highly controversial social phenomena like same-sex marriage and transgender people, they failed to recognize people with disabilities as sexual beings [48, 73].

Scheutz and Arnold [76] argue that 'using sex robots have less to do with what a sex robot is, or how sex with a robot is categorized, than they do with different takes on the conditions and purposes of both personal relationships and society's interests.' This article takes a step forward in this direction by proposing the use of sex robots in care to empower persons with disabilities to exercise their sexual rights, which society too often disregards [103].

In this article, we investigate first to what extent the concept of care may or may not include sex as a fundamental aspect. Second, we review existing robots for sex care purposes. In the third section, we explore the potential realization of sex robots for care purposes. We also anticipate drawbacks concerning the use and implementation of such types of robots in healthcare.

Our contribution does not endeavor in making decisive judgments for or against the use of sex robots in the care of persons with disabilities. With utmost respect to the potential target users, we aim to create a room for discussion with the Human-Robot Interaction community about converging and diverging opinions on the topic of robots for sex care. Hopefully, these discussions will serve as a step forward in raising awareness of the lack of attention concerning the sexual rights of the disabled and provide the basis for envisaging solutions in this arena, including informing the policy debate around the regulation of robots and setting the scene for further research.

\section{PEOPLE WITH DISABILITIES AND THEIR SEXUAL RIGHTS}

The World Health Organization defines sexual health as the 'state of physical, mental, and social well-being concerning sexuality. It requires a positive and respectful approach to sexuality and sexual relationships, as well as the possibility of having pleasurable and safe sexual experiences, free of coercion, discrimination, and violence' [104].

Although sexuality is a central aspect of human experience, awareness, and knowledge do not come straightforward for disabled populations. On the contrary, evidence suggests that this is largely constrained, pathologized, and ignored in mental health settings [96], whereas if society truly supported human dignity, it should take the claims of those who lose the ability to be sexual sincerely and make reasonable efforts to help in this respect [35].

Many aspects constrain how people with disabilities experience and engage with themselves as sexual beings, including their particular disability and sociocultural, religion, economics, age, and gender factors [2,35]. Still, some of the most worrisome barriers come from the very same institutions. Some researchers highlight that people with intellectual disabilities are 'purposefully misinformed about sexual health to reinforce fears as a means of inhibiting sexual activity' [78]. Others that healthcare providers consider that 'people with intellectual disabilities or other disabilities should not have a sexual life, reproduce or look after children, and therefore should not need sexual and reproductive health services' [103]. Other quantitative studies show that non-disabled people perceive people with physical disabilities as having fewer sexual and reproductive rights [29], sometimes even asexual [78], especially women [100].

If a person is physically disabled, physical disability may prevent that person from satisfying her sexual needs. For instance, think of a person who is deprived of her upper-limbs or is paralyzed [73]. On the other side, people experiencing mental illness may experience sexuality and intimate relationships very differently for several reasons [96]. Some of them relate to their mental health condition that often leads them to poor sexual outcomes, including high rates of sexually transmitted infections and blood-borne disease, unplanned pregnancy, and sexual assault [33]. Others are structural and social factors associated with mental illness, including stigma [51, 64]. The medication they take also decreases their sexual desire levels or physical, almost leading to sexual dysfunction [68].

It could be that organizations are confused about the legality of offering support to a safe sexual expression [4]. However, since 1993, the United Nations has stressed that persons with disabilities should enjoy family life and personal integrity, and should 'not be denied the opportunity to experience their sexuality, have sexual relationships and experience parenthood' (Rule 9, para. 2) [94]. The Convention on the Rights of Persons with Disabilities [95] also highlights that people with disabilities should have the right to enjoy the highest standard of health without discrimination based on disability. It also mentioned that States should 'provide persons with disabilities with the same range, quality, and standard of free or affordable health care and programs as provided to other persons, including in the area of sexual and reproductive health and population-based public health programs.'

Studies report that attitudes towards sexuality in the general population are more favorable than those with some disability $[52,103]$. However, age and occupation play a significant role: while staff education and attitudes towards sex rights of persons with disabilities are not related, younger (20-29) and managers are usually more optimistic than older, direct workers concerning sex in institutional care [52].

It seems that the full realization of the sexual rights of persons with disabilities requires more research and policies that understand the intersection of people, disability, and sexual rights [2]. In Jecker's words, 'just as society has the power to insult people's dignity by shaming and stigmatizing their sexual desires and behavior, it has the power to support dignity and serve as a bulwark against shame' [35]. These policies could represent a step forward in treating people with disabilities in a 
dignity-respecting and non-discriminatory fashion concerning their sexual rights [26].

Some countries have reflected on how the general and abstract idea of the sexual rights of people with disabilities can be translated into concrete actions. In the Netherlands, for instance, they materialize it into what has been called sex care. Although this concept lacks a precise definition, Nwanazia [61] defines sex care as a 'sexual service for people with severe physical or mental disabilities (...) often done by professionals with a background in health care (...) focused on intimacy, physical touch and sexual satisfaction for disabled clients.' In Europe, there is a platform called the European Platform Sexual Assistance for Persons with Disabilities (EPSEAS) that brings together different non-profit organizations offering sexual services for people with disabilities.

However, while sex care is good progress in materializing the abstract idea of supporting a person's sexual needs, it raises many questions. First, it is not clear the necessary knowledge required for satisfying the sexual needs of a disabled person and whether there should be minimum safeguards. Second, sex work is controversial concerning sex workers' legal status and the lack of institutionalized structure. Sex work has traditionally involved many related crimes. They are illegal in many jurisdictions, and they oftentimes mask crimes that range from violence against prostitutes to human trafficking. In this respect, it is highly controversial to think that publicly available funds should cover these services. For these reasons, sex care has been far from successful. There are very few (if none) studies considering the viability of sex care for disabled persons, suggesting a highly relevant area for further research.

\section{SEX ROBOTS}

\subsection{Sex Robot Characteristics}

Previous work adapted the ISO 8373-2012 definition of a robot to define sex robots as service robots that perform actions contributing directly towards improvement in the satisfaction of the sexual needs of a user [26]. Following that definition, which requires a robot to be programmable and incorporate a degree of freedom, all other electronic sex devices are excluded here. Sex robots incorporate a range of technologies that distinguishes them from mere silicone sex dolls that emit computeresque voice from a perpetually agape mouth, with restricted limb movements and no physical feedback. Sex robots can display realistic sexrelated body movements, have sensors to react in real-time to user interaction.

A recent review [26] identified 12 robots that meet the definition mentioned above of a sex robot. While those 12 sex robots were in varying states (i.e., either purchasable, in development, or not for sale), they were actualized fully or in part. The 12 sex robots identified were TrueCompanion's Roxxxy and Rocky, Emma, and other models from Shenzhen All Intelligent Robot Technology (AI-Tech), Android Love Dolls' Robot Sex Dolls, Realdollx models, Fantasy AI Silicone Love Doll, Synthea Amatus' AI Dolls (including Samantha), ExDoll's
Xiaodie, DS Doll Robotics' first and second-generation Robot Doll Heads, Gabriel2052, and Android Robot Store's Android Robot Dolls [26]. The review also developed a list of categories (and subcategories) that capture the different characteristics of sex robots. Those categories were: Gender/body type, Embodiment, Mobility and battery, Smart connectivity, Autonomous sexual awareness, Autonomous sexual responsiveness, Non-autonomous actionability, Sociability, Learning, Human-likeness (or human mimicry), and Hygiene [26].

Since that review was conducted throughout Mid-2019, no new sex robots have entered the market. However, there have been a few notable developments. Cloud Climax, the UK agent for AI-Tech, has upgraded Emma to include moving eyes (i.e., movement of eyeballs) [3]. More than blinking and eyebrow movements, moving eyes gives the impression that a sex robot is looking around. They also intend to equip Emma with the capacity to breathe, which presumably involves an expanding and collapsing chest cavity [54]. However, this has yet to be implemented. Abyss Creations have added two new models to the Realdollx lineup, Serenity and Nova. Moving eyes have also been newly integrated into the Realdollx lineup [1]. Abyss Creations [1] claim that '[b]uilt-in cameras are in development,' but no further details are given.

\subsection{Human-Robot Interaction and Sex Robots}

The topic of sex robots yields mixed reactions in the HumanRobot Interaction (HRI) community, raising both concerns and potential benefits. Some concerns include deception and encouraging users to attribute thoughts, emotions, and bonds to robots wrongly $[43,58,75,82]$, desensitization and reinforcement of poor sexual behaviors [12, 47, 82], and the objectification of women [70, 82]. Several potential benefits include alternatives to prostitutes in the provision of sex care [44], avoiding challenging the sexual rights of others [16], and curbing sex exploitation, sex trafficking, and sex slavery as a result of the reduction of human prostitution [74].

Much of the impacts of sex robot use remain unknown. In a 2020 review of sex doll and sex robot design, use, and effects, Döring, Mohseni, \& Walter [18] found no published empirical studies that address sex robot use reported by sex robot users. Until empirical research on sex robot use is completed, the benefits and consequences to users remain unconfirmed.

The role of sex roboticists and sex robot designers is complicated $[14,15,38]$. One encounters problematic design considerations in the design process, such as robot rape [14] and the usual focus on straight male needs [77]. The HRI literature on the design of sex robots offers some guidance for roboticists working in this area, but more is needed going forward. In response to the concern about sex robots objectifying women, Danaher [13] suggests pursuing feminist sex robots. Drawing insights from feminist pornography, designing sex robots with a feminist approach encourages realistic and fair depictions of sexuality, more female voices in production and distribution, and inclusive social environments and conversations on the use of sex robots [13]. A recent study [87] reporting on sex doll use 
uses empirical findings to glean design considerations for sex robots. Some insights include considering the intimate fantasies that users construct with sex dolls and how that experience is supported or contradicted with the customization of sex robots, and being aware that users could develop intimate attachment for these artifacts that they perceive to require care and how this calls for a design that accounts for long-term use [87].

Other HRI publications present additional sex robot design considerations on speech [8], kissing [9], embodiment [21, 32, 98], consent [40], and accounting for ethical concerns emerging from anthropomorphization, including possible user emotional vulnerability, deception, and prevention from engaging in relationships with humans [62]. Some of the HRI literature also makes recommendations on the sex robot design process, such as calling for the involvement of scientists engaged in sexual research [21] and applying existing knowledge during the design phase about the philosophy of love, the ethics of loving relationships, and the value of the erotic [88].

\subsection{Growing Acceptance of Sex Robots}

Scheutz and Arnold [76] conducted a methodical survey of the public opinion towards robots and sex. They concluded that, overall, participants considered 'more or less strongly as appropriate' different uses of sex robots, including their use for disabled people, sex education, to improve self-esteem and overall psychological health, or to improve hormone levels of people with infrequent sex lives.

Although there have been no new sex robots entering the market, as well as only a few publicly confirmed advances in the technology, acceptance of sex robots has risen. According to a study conducted by YouGov in 2020, 'more than one in five Americans (22\%) say they would consider having sex with a robot,' which is $6 \%$ more than the national rate in 2017 [59].

Other trends related to sex robot use are experiencing interesting shifts towards acceptability also. For instance, to the question 'Would you consider cheating if you had a partner who had sex with a robot,' there was a decrease from $32 \%$ to $27 \%$ of interviewed Americans that answered 'yes' to the answer, 'probably because engaging in sex with a robot as closer to masturbation (31\%) than actual intercourse (14\%)' [59]. Moreover, $42 \%$ of the respondents believed that having sexual intercourse with robots is safer than with other human strangers (only 7\% thought it would be less secure).

In other recent publications, sex robots have not been put in the best light. A satirical article written as if it was the journal of a sex robot worker concludes: 'I figured it was a good time to stop for the day and recharge. I think I've learned what men want. They just want to be intimate, feel validated, and get off with a lubricated servo that's capable of one thousand pulsations a second' [55]. From the simple over-exaggeration of battery capacity to the gross fetishization and stereotyping of all users as (1) men and (2) those seeking 'one thousand pulsations a second,' such media about sex robots spreads misinformation. This kind of discourse disregards the potential use of sex robots as aids in sex care, which could improve the well-being of people with disabilities and advance their care towards equity. However, more research is needed to support this.

\section{SEX ROBOT APPLICATIONS FOR SEX CARE}

Progress in medicine may serve to revisit social norms that currently represent a barrier to sexuality in specific populations [46]. Advances in the sex robot industry may also shape how sex is conceived for the care sector. Bendel [7], for instance, already classified healthcare robots as surgical, therapeutic, nursing, and sex robots, arguing that 'a sex life that fulfills the individual needs surely contributes to health and well-being.'

Sex robots are not mere inanimate masturbation aid. They also include features that ascribe sociability and human-likeness to robot-mediated sexual relationships. In this sense, Döring et al. [18] argue that sex robots 'are meaningful and possibly helpful precisely because they are not substitutes for real humans but are sociotechnical entities for parasocial use and play.' Others have argued otherwise, holding that a sex robot only facilitates masturbation, not sexual intercourse, which requires another human [83].

Sex robots have many sexual characteristics and capabilities that might prove useful in fulfilling the sexual desires of those in disability care. Using thematic analysis [56], three key themes that capture those uses were identified: sexual, emotional, and educational. Discussing these themes with the HRI community will indeed point to more research to understand how robot technology might help specific populations and under which circumstances this could be considered a positive or a harmful aid.

\subsection{Sexual Theme}

Recent literature proves no loss of libido in the disabled adult population [41, 92]. People with intellectual disabilities have sexual needs and engage in sex and long-term relationships [20]. However, barriers to sexual expression for this group exist in care services, including institutionalized living, lack of privacy, and lack of knowledge about sexuality and opportunities to express themselves [11]. For those with physical disabilities, while sexual esteem, satisfaction, and frequency seem to trend lower as the severity of physical disability increases [50], sexual needs are still salient [39].

As a tool, sex robots could help provide a safe environment for persons with disabilities to explore sexuality. Some sex robots, such as Rocky or Roxxxy, can perform simple sexual movements, i.e., moving back and forth from the user rather than requiring them to move. This function could be useful for those with physical disabilities as it affords the user the ability to use a sex robot without high physical cost. Furthermore, sex robots that enable masturbation, such a Gabriel2052 with a robotic arm or a Realdollx model with a massaging function, could cater to a physically disabled user's need.

Still in the sexual theme, but on the tamer side of companionship, is intimacy. The literature shows that disabled persons seek intimacy $[49,81]$. For men with physical 
disabilities, nude cuddling is a significant predictor of sexual satisfaction [50]. This kind of intimacy could be realized with sex robots, much like sex dolls [87]. For example, Emma has internal heating systems that make the sex robot warm to the touch, intentionally simulating a person. Similarly, deep kissing is important for sexual satisfaction in women with physical disabilities [50]. Sex robots, such as the Realldollx models, have dynamic mouth movements that could imitate kissing. Exoskeletons for sex purposes enable a sex robot to walk and move its arms, such as those by the Android Robot Store. As another type of physical intimacy, walking and limb articulation functions could enable a sex robot and user to walk together and hold hands.

\subsection{Emotional Theme}

While sex robots have a clear functional goal to satisfy users' sexual needs, manufacturers profoundly stress their technology's emotional support side. For example, Emma uses voice recognition to acknowledge the user as an individual. Roxxxy and Realdollx models have personalities that the user can select from to best suit their needs. In the case of Realdollx models, the personality adapts to the user over time, using deep learning conversational models. Samantha and other sex robots from Synthea Amatus are equipped with human-like cues, such as likes and dislikes, laughter, and moods. They can make faces, smile, frown, and look attentive.

Sexual acts manifest different physical feelings, such as bodily pleasure and enjoyment, but they are also closely linked with emotions. These emotional features seem to advance the idea that sex robots could support positive, close encounters with persons beyond purely sexual experiences. People with severe physical and mental health disabilities that lack social skills require patience from those who socially interact with them [34, 53]. Disabled persons might find a robot's intrinsic patience valuable, as they could converse with a sex robot as much as they need/want to without the robot losing patience.

Robots for sex care could represent the uniting of emotional support and sexual companionship that benefit users in disability care [35]. Consider the persistent issue of LGBTQ+ disabled persons lacking the adequate support and service provision to explore sexuality, experience relationships, and be out and proud $[60,102]$. Rocky, an android sex robot, could help a closeted gay man who never pursued gay relationships or sexual relations. Some closeted, disabled gay men may be afraid to express their gay orientation with others in care settings for fear of judgment, denial, anxiety, or inexperience. In this instance, introducing Rocky in this specific context could allow that person to grow sexually and emotionally without fear.

A sex robot might be a non-judgmental solution for sexual exploration among users, including disabled persons. Users could utilize gendered sex robots to explore their sexuality if they never had the chance previously [45]. Realdollx models can be fitted with a 'transgender converter,' enabling the possibility for sexual exploration with sex robots to go beyond the gender binary.

\subsection{Educational Theme}

Murphy \& O'Callaghan [57] conducted a study asking adults with intellectual disabilities and young persons to assess their sexual knowledge on vulnerability to abuse. The study revealed that participants with intellectual disabilities scored low concerning their understanding of consent and abuse, suggesting a profound need to have more and better sex education for persons with intellectual disabilities to exercise their sexual rights while also protecting themselves [57].

Sex robots could help disabled persons with cognitive challenges learn about sexuality and emotions, including consent. This is important because abusive sexual behavior in disabled populations is unsettlingly common [31, 78]. Sex robots might serve an educational purpose by providing on-going, practical sex education for these persons. For instance, the robot Samantha can detect aggressive touching from a user using sensors across the body and turn itself off without giving sexual feedback. In this respect, cognitively challenged people may lack the awareness or understanding to determine if a potential sexual partner is giving consent or not. The robot Samantha could teach those individuals the consent process by having to be gently touched by the user to activate.

\section{SOCIETAL AND DESIGN IMPLICATIONS}

\subsection{Sex Robot in Care Implications}

It is also essential to notice that, paradoxically, technology increasingly has a habit of being both the source of and the solution to societal problems, and robots are no exception [6, 24]. There are countless examples of how technology has been proposed to solve inadequate engineering practice, government policy failures, or modern consumerism outcomes, showing how technological fixes have cultural, ethical, and political implications [6, 37]. Sex robots may offer a good solution to support human dignity for disabled populations, but these robots may also bring other unexpected consequences.

In this sense, sex robots in care are still under exploration $[23,26]$. Even the use of care robots still faces challenges [36, 63]. Thus, the literature lacks a comprehensive understanding of the impacts that sex robots in care may have on disabled populations. Table 1 collates recent studies reflecting upon care robot implications that anticipate some of these impacts $[23,79$, 93, 97, 99]. After that, Table 2 reflects on the added implications of sex robots found in the literature $[12,16,17,22,25,35,43,44$, 47, 69-72, 74-76, 80, 82-84, 88-90, 101]: 
Table 1: Legal and ethical implications of the use and development of robots for care purposes

\begin{tabular}{|c|c|}
\hline $\begin{array}{l}\text { Care-related } \\
\text { consideration }\end{array}$ & Explanation \\
\hline $\begin{array}{l}\text { Human-robot } \\
\text { safe interaction }\end{array}$ & $\begin{array}{l}\text { Robots may challenge the physical and } \\
\text { mental integrity of the users. Both } \\
\text { physical and cognitive safety should be } \\
\text { protected. }\end{array}$ \\
\hline $\begin{array}{l}\text { Allocation of } \\
\text { responsibility }\end{array}$ & $\begin{array}{l}\text { Depending on the degree of control a } \\
\text { user has, the question of who is } \\
\text { responsible if something goes wrong } \\
\text { may abound. }\end{array}$ \\
\hline $\begin{array}{l}\text { Privacy and data } \\
\text { protection loss }\end{array}$ & $\begin{array}{l}\text { Always-on robotic devices that monitor } \\
\text { the activities of users may challenge the } \\
\text { protection of their data protection and } \\
\text { privacy rights. }\end{array}$ \\
\hline $\begin{array}{l}\text { Autonomy } \\
\text { restriction }\end{array}$ & $\begin{array}{l}\text { Task delegations from the human to the } \\
\text { machine risk overriding the autonomy } \\
\text { and independence of a person. }\end{array}$ \\
\hline $\begin{array}{l}\text { Deception and } \\
\text { infantilization }\end{array}$ & $\begin{array}{l}\text { Mimicking life-like and human states } \\
\text { may lead to questioning the authenticity } \\
\text { of the relationship, or deceiving or } \\
\text { infantilizing the user. }\end{array}$ \\
\hline $\begin{array}{l}\text { Objectification } \\
\text { and loss of } \\
\text { control }\end{array}$ & $\begin{array}{l}\text { Insensitive use of robots risks treating } \\
\text { users as if they were not sentient beings. }\end{array}$ \\
\hline $\begin{array}{l}\text { Human-human } \\
\text { interaction } \\
\text { decrease }\end{array}$ & $\begin{array}{l}\text { Human-robot interaction may } \\
\text { exacerbate existing user loneliness and } \\
\text { increase neglection by relatives and } \\
\text { society. }\end{array}$ \\
\hline $\begin{array}{l}\text { Long-term } \\
\text { consequences }\end{array}$ & $\begin{array}{l}\text { Technology, including robots and AI, } \\
\text { may have long-term consequences that } \\
\text { might be difficult to foresee before mass- } \\
\text { adoption and continuous use. }\end{array}$ \\
\hline
\end{tabular}

\subsection{Anticipation, Reflection, and Action}

These reflections anticipate that the design and implementation of sex robots in care is not straightforward and requires careful thought. In Johnston's words [37], 'modern problems cannot be reduced to mere engineering solutions over the long-term; human goals are diverse and constantly changing.' A great start would be to follow initiatives promoting reflection upon the consequences and outcomes of technological research and development (R\&D) that foster the incorporation of societallyoriented considerations into the research or the design process [85]. These exercises would entail researchers and designers working in this area to [5, 42, 86]: (1) anticipate potential adverse consequences of their work to build socially robust and risk-free research; (2) reflect mindfully about their work, framing issues, problems, and proposed solutions; (3) be inclusive and conduct research not only for society but also with society, thus involving a wide range of stakeholders from the early stages of the process; (4) respond to circumstances that no longer align with society's continually evolving needs and public values; and (5) be transparent about the research to enable public scrutiny and dialogue.

Table 2: Summaries of the main implications of sex robot use and development for care purposes

\begin{tabular}{ll}
\hline $\begin{array}{l}\text { Sex care-related } \\
\text { consideration }\end{array}$ & Explanation \\
\hline Dehumanizing care & $\begin{array}{l}\text { Care robots might dehumanize care } \\
\text { practices. The dehumanizing effects } \\
\text { of sex robots are unclear. }\end{array}$ \\
\hline $\begin{array}{l}\text { Reinforcing } \\
\text { existing biases }\end{array}$ & $\begin{array}{l}\text { Sex robots reflect sexist, racist, ableist, } \\
\text { ageist, and heterosexist attitudes. }\end{array}$ \\
\hline $\begin{array}{l}\text { Challenging } \\
\text { dignity }\end{array}$ & $\begin{array}{l}\text { A sex robot in care might challenge } \\
\text { the dignity of specific populations. }\end{array}$ \\
\hline $\begin{array}{l}\text { Prostitution and } \\
\text { rape }\end{array}$ & $\begin{array}{l}\text { Robots may allow for the } \\
\text { reproduction of morally questionable } \\
\text { behaviors that may replicate in } \\
\text { society. }\end{array}$ \\
\hline $\begin{array}{l}\text { Distorting } \\
\text { relationships } \\
\text { further }\end{array}$ & $\begin{array}{l}\text { Users of sex robots, including those } \\
\text { for sex care, may believe that there is } \\
\text { a close bidirectional relationship } \\
\text { when, in reality, those bonds are }\end{array}$ \\
$\begin{array}{l}\text { unidirectional. } \\
\text { Techno- } \\
\text { solutionism and } \\
\text { the never-ending } \\
\text { problem solving }\end{array}$ & $\begin{array}{l}\text { Robots may offer opportunities but } \\
\text { create other problems, like } \\
\text { desensitization towards sexual } \\
\text { behavior, justification or } \\
\text { reinforcement of one's poor actions } \\
\text { through the distortion of one's } \\
\text { cognition from frequent sex robot use, } \\
\text { the objectification of women, and } \\
\text { reinforcement of existing sexism or } \\
\text { machismo in society. }\end{array}$ \\
\hline & \\
&
\end{tabular}

In doing so, robot developers will realize the need to follow other methods to help see what these public values are, what purpose these robots serve to society, and how existing relationships will change. In this particular context involving disabled populations, it will be essential to anticipate the specific physical and sex-related needs that disabled persons might have. Methods that cater to the creation of robots to the particular needs of users include value-sensitive design [27], care-centered value-sensitive design [99], and values in motion design [65-67]. In this respect, the engagement between sex robot makers, care providers, and persons with disabilities may help configure a more-than-human-centered approach to sex robots in care [30].

Following these approaches would allow for new avenues in how society conceives robots. For instance, given current attitudes and narratives concerning sexuality, it is of little astonishment that sex robots are usually not targeted to people with disabilities but young, non-disabled, and typically straight men [35]. In this respect, the HRI community could help generate counternarratives about potential sexual futures that include older adults, persons with disabilities, different sexual 
orientations, and sex robots to counteract the technological determinism ruling our contemporary narratives [30].

\section{CONCLUSION}

This paper discussed whether sex robots could serve as a step forward in realizing the sexual rights of persons with disabilities. Whether social, psychological, or biological, several difficulties may negatively impact an individual's well-being, their experience of mental health services, and their recovery. Some of those impediments in physically and mentally disabled populations prevent them from experiencing the pleasures of life, including having sexual relationships and realizing their sexual rights. Other barriers often relate to the stigmatization of older adults and disabled population needs, which are often unfounded. Technology offers the possibility to truly empower disabled people and end the remaining silences about sexuality for this part of the population [2, 35]. In this respect, society should take reasonable steps to support human capabilities as part of a more all-inclusive duty to respect human dignity [35].

Still, while sex robots may support human dignity for disabled populations, these robots may also bring other unexpected consequences. Robot technology may have moral implications, contribute to the loss of human contact, reinforce existing socioeconomic inequalities, or fail to deliver good care [26]. There is no proof that sex robot technology is going to be any different. Moreover, these technologies might have longterm catastrophic or existential risks and might have to 'be subject to planning and mitigation efforts commensurate with their expected impact' [28].

If responsible, innovation may contribute to ensuring a desirable future for humanity. In this paper, we call for the HRI community to mindfully think about the potential sex robots may have in care. However, we alert them that this area of research is very sensitive and may have ulterior implications not only for particular subjects but also for society. In this vein, researchers in HRI need to reflect, together with other disciplines, end-users, and policymakers, how this research can meaningfully contribute to society [5].

\section{ACKNOWLEDGMENTS}

Part of this project was funded by the LEaDing Fellows Marie Curie COFUND fellowship, a project that has received funding from the European Union's Horizon 2020 research and innovation programme under the Marie Skłodowska-Curie Grant Agreement No. 707404.

\section{REFERENCES}

[1] Abyss Creations. 2020. Realdollx. https://www.realdoll.com/realdoll-x/

[2] Renu Addlakha, Janet Price, and Shirin Heidari, 2017. Disability and sexuality: claiming sexual and reproductive rights. Reproductive Health $\begin{array}{lllll}\text { Matters } & 25, & 50 & \text { (Jul, } & \text { 2017), }\end{array}$ https://doi.org/10.1080/09688080.2017.1336375

[3] AI-Tech UK. 2020. Emma the AI Robot. https://ai-aitech.co.uk/emma-the-airobot

[4] Natasha Alexander and Miriam T. Gomez, 2017. Pleasure, sex, prohibition, intellectual disability, and dangerous ideas. Reproductive Health Matters 25, 50 (May, 2017), 114-120. DOI: https://doi.org/10.1080/09688080.2017.1331690
[5] Laura Aymerich-Franch and Eduard Fosch-Villaronga, 2020. A self-guiding tool to conduct research with embodiment technologies responsibly. Frontiers in Robotics and AI 7, 22 (Feb, 2020), 1-5. DOI: https://doi.org/10.3389/frobt.2020.00022

[6] Zygmunt Bauman. 2013. Liquid love: On the frailty of human bonds. John Wiley \& Sons.

[7] Oliver Bendel, 2015. Surgical, therapeutic, nursing and sex robots in machine and information ethics. In Machine Medical Ethics, Simon P. van Rysewyk and Matthijs Pontier (Eds.). Springer, 17-32. DOI: https://doi.org/10.1007/9783-319-08108-3_2

[8] Oliver Bendel, 2018. SSML for sex robots. In Love and Sex with Robots, Adrian D. Cheok and David Levy (Eds.). Springer, 1-11. DOI: https://doi.org/10.1007/978-3-319-76369-9 1

[9] Adrian D. Cheok, David Levy, and Kasun Karunanayaka, 2016. Lovotics: Love and sex with robots. In Emotion in Games: Theory and Praxis, Kostas Karpouzis and Georgios N. Yannakakis (Eds.). Springer, 303-328. DOI: https://doi.org/10.1007/978-3-319-41316-7_18

[10] Chantal Cox-George and Susan Bewley, 2018. I, sex robot: the health implications of the sex robot industry. BMF Sexual \& Reproductive Health 44, 3, 153-154. DOI: http://dx.doi.org/10.1136/bmjsrh-2017-200012

[11] Monica Cuskelly and Linda Gilmore, 2007. Attitudes to sexuality questionnaire (individuals with an intellectual disability): scale development and community norms. F. Intellect. Dev. Disabil. 32, 3 (Sep, 2007), 214-221. DOI: https://doi.org/10.1080/13668250701549450

[12] John Danaher, 2017. Robotic rape and robotic child sexual abuse: should they be criminalised? Criminal Law and Philosophy 11, 1 (Dec, 2014), 71-95. DOI: https://doi.org/10.1007/s11572-014-9362-x

[13] John Danaher, 2019. Building better sex robots: Lessons from feminist pornography. In AI Love You, Yuefang Zhou and Martin H. Fischer (Eds.). Springer, 133-147. DOI: https://doi.org/10.1007/978-3-030-19734-6_7

[14] John Danaher and Neil McArthur. 2017. Robot Sex: Social and Ethical Implications. MIT Press.

[15] Kate Devlin. 2018. Turned On: Science, Sex and Robots. Bloomsbury Publishing.

[16] Ezio Di Nucci, 2017. Sex robots and the rights of the disabled. In Robot Sex: Social and Ethical Implications, John Danaher and Neil McArthur (Eds.). MIT Press, 73-88. DOI: https://doi.org/10.7551/mitpress/9780262036689.001.0001

[17] Nicola Döring and Sandra Poeschl-Guenther, 2018. Sex toys, sex dolls, sex robots: Our under-researched bed-fellows. Sexologies 27, 3 (Jul, 2018), 51-55 DOI: https://doi.org/10.1016/j.sexol.2018.05.009

[18] Nicola Döring, M Rohangis Mohseni, and Roberto Walter, 2020. Design, use, and effects of sex dolls and sex robots: scoping review. Fournal of medical Internet research 22, 7 (Jul, 2020), e18551. DOI: https://doi.org/10.2196/18551

[19] Simon Dubé and Dave Anctil, 2020. Foundations of Erobotics. Int f Soc Robot, (Oct, 2020), 1-29. DOI: https://doi.org/10.1007/s12369-020-00706-0

[20] Gillian Eastgate and Nicholas G. Lennox, 2003. Primary health care for adults with intellectual disability. Aust. Fam. Physician 32, 5 (May, 2003), 330-333.

[21] Christiane Eichenberg, Marwa Khamis, and Lisa Hübner, 2019. The attitudes of therapists and physicians on the use of sex robots in sexual therapy: Online survey and interview study. F Med Internet Res 21, 8 (Aug, 2019), e13853. DOI: https://doi.org/10.2196/13853

[22] European Parliament Resolution on Civil Law Rules on Robotics. 2017 http://www.europarl.europa.eu/doceo/document/TA-8-2017-0051_EN.html

[23] Eduard Fosch Villaronga, 2017. Towards a legal and ethical framework for personal care robots. Analysis of person carrier, physical assistant and mobile servant robots. Erasmus Mundus in Law, Science, and Technology Doctoral dissertation. http://amsdottorato.unibo.it/8203/

[24] Eduard Fosch-Villaronga. 2019. Robots, healthcare, and the law: Regulating automation in personal care. Routledge.

[25] Eduard Fosch-Villaronga and Jordi Albo-Canals, 2019. "I'll take care of you," said the robot, Paladyn, fournal of Behavioral Robotics 10, 1 (Jan, 2019), 77-93. DOI: https://doi.org/10.1515/pjbr-2019-0006

[26] Eduard Fosch-Villaronga and Adam Poulsen, 2020. Sex care robots. Paladyn, Journal of Behavioral Robotics 11, 1 (Jan 2020), 1-18. DOI: https://doi.org/10.1515/pjbr-2020-0001

[27] Batya Friedman, Peter H. J. Kahn, and Alan Borning, 2006. Value sensitive design and information systems. In Human-Computer Interaction and Management Information Systems: Foundations (Advances in Management Series), Ping Zhang and Dennis Galletta (Eds.). M. E. Sharpe, 348-372. DOI: https://doi.org/10.1007/978-94-007-7844-3_4

[28] Future of Life Institute. 2017. Can We Properly Prepare for the Risks of Superintelligent AI? https://futureoflife.org/2017/03/23/ai-risks-principle/ 
[29] Alexandra Gartrell, Klaus Baesel, and Cornelia Becker, 2017. "We do not dare to love": women with disabilities' sexual and reproductive health and rights in rural Cambodia. Reproductive Health Matters 25, 50 (May, 2017), 31-42. DOI: https://doi.org/10.1080/09688080.2017.1332447

[30] Elisa Giaccardi and Johan Redström, 2020. Technology and more-thanhuman design. Design Issues 36, 4 (Sep, 2020), 33-44. DOI https://doi.org/10.1162/desi_a_00612

[31] Nechama W. Greenwood and Joanne Wilkinson, 2013. Sexual and reproductive health care for women with intellectual disabilities: a primary care perspective. International fournal of Family Medicine 2013, 1-8. DOI: https://doi.org/10.1155/2013/642472

[32] Lynne Hall, 2017. Sex with robots for love free encounters. In Love and Sex with Robots, Adrian D. Cheok, Kate Devlin, and David Levy (Eds.). Springer, 128-136. DOI: https://doi.org/10.1007/978-3-319-57738-8_12

[33] Agnes Higgins, Philip Barker, and Cecily Begley, 2006. Sexual health education for people with mental health problems: What can we learn from the literature? Fournal of Psychiatric and Mental Health Nursing 13, 6 (Dec, 2006), 687-697. DOI: https://doi.org/10.1111/j.1365-2850.2006.01016.x.

[34] Navaneetham Janardhana, Shravya Raghunandan, Dodala M. Naidu, L. Saraswathi, and Valli Seshan, 2015. Care giving of people with severe mental illness: An Indian experience. Indian fournal of Psychological Medicine 37, 2 (Apr, 2005), 184-194. DOI: https://dx.doi.org/10.4103\%2F0253-7176.155619

[35] Nancy S. Jecker, 2020. Nothing to be ashamed of: sex robots for older adults with disabilities. Journal of Medical Ethics 47, 1 (Aug, 2020), 26-32. DOI: http://dx.doi.org/10.1136/medethics-2020-106645

[36] Rose-Marie Johansson-Pajala and Christine Gustafsson, 2020. Significant challenges when introducing care robots in Swedish elder care. Disability and Rehabilitation: Assistive Technology, (Jun, 2020), 1-11. DOI: https://doi.org/10.1080/17483107.2020.1773549

[37] Sean F. Johnston, 2018. The technological fix as social cure-all: Origins and implications. IEEE Technology and Society Magazine 37, 1 (Mar, 2018), 47-54. DOI: https://doi.org/10.1109/MTS.2018.2795118.

[38] Deborah G. Johnson and Mario Verdicchio, 2020. Constructing the meaning of humanoid sex robots. Int 7 of Soc Robotics 12, (Aug, 2019), 415-424. DOI: https://doi.org/10.1007/s12369-019-00586-z

[39] Shanna K. Kattari, 2014. Sexual Experiences of Adults with Physical Disabilities: Negotiating with Sexual Partners. Sex and Disabil 32, (Sep, 2014), 499-513. DOI: https://doi.org/10.1007/s11195-014-9379-z

[40] Ellen M. Kaufman, 2020. Reprogramming consent: implications of sexual relationships with artificially intelligent partners. Psychology \& Sexuality 11, 4 (Apr, 2020), 372-383. DOI: https://doi.org/10.1080/19419899.2020.1769160.

[41] Remigiusz J. Kijak, 2011. A desire for love: considerations on sexuality and sexual education of people with intellectual disability in Poland. Sexuality and disability 29, 1 (Mar, 2011), 65-74. DOI: https://doi.org/10.1007/s11195010-9184-2

[42] Frank Kupper, Pim Klaassen, Michelle Rijnen, Sara Vermeulen, and Jacqueline Broerse. 2015. Report on the Quality Criteria of Good Practice Standards in RRI. Athena Institute, VU University Amsterdam.

[43] Patrick Lin, Keith Abney, and George Bekey, 2011. Robot ethics: Mapping the issues for a mechanized world. Artificial Intelligence 175, (5-6), 942-949. DOI: https://doi.org/10.1016/j.artint.2010.11.026

[44] David Levy. 2007. Robot prostitutes as alternatives to human sex workers. In Proceedings of the IEEE International Conference on Robotics and Automation. Retrieved from http://www.prostitutionresearch.com/wpcontent/uploads/2012/01/Robot-Prostitutes-as-Alternatives.pdf

[45] David Levy. 2009. Love and Sex with Robots: The Evolution of Human-Robot Relationships. Harper Collins.

[46] Manjula Lusti-Narasimhan and John R. Beard, 2013. Sexual health in older women. Bulletin of the World Health Organization 91, (May, 2013), 707-709. DOI: http://dx.doi.org/10.2471/BLT.13.119230

[47] Marie-Helen Maras and Lauren R. Shapiro, 2017. Child sex dolls and robots: More than just an uncanny valley, fournal of Internet Law 21, 6, 3-21.

[48] Jane Maxwell, Julia W. Belser, and Darlena David. 2006. A Health Handbook for Women with Disabilities. Hesperian.

[49] Marita P. McCabe, Robert A. Cummins, and Amada A. Deeks, 2000. Sexuality and quality of life among people with physical disability. Sexuality and Disability 18, 2 (Jun, 2000), 115-123. DOI: https://doi.org/10.1023/A:1005562813603

[50] Marita P. McCabe and George Taleporos, 2003. Sexual Esteem, Sexual Satisfaction, and Sexual Behavior Among People with Physical Disability.
Arch Sex Behav 32, 4 (Aug, 2003), 359-369. DOI: https://doi.org/10.1023/A:1024047100251

[51] Edward McCann, 2003. Exploring sexual and relationship possibilities for people with psychosis - A review of the literature. Fournal of Psychiatric and Mental Health Nursing 10, 6 (Dec, 2003), 640-649. DOI: https://doi.org/10.1046/j.1365-2850.2003.00635.x

[52] Rebecca Meaney-Tavares and Susana Gavidia-Payne, 2012. Staff characteristics and attitudes towards the sexuality of people with intellectual disability. Fournal of Intellectual and Developmental Disability 37, 3 (Jul, 2012), 269-273. DOI: https://doi.org/10.3109/13668250.2012.701005

[53] Mental Health First Aid Australia. 2011. Guidelines for Carers of Someone with a Mental Illness. https://mhfa.com.au/sites/default/files/1407W_MHFA_carers_guidelinesA4V2.pdf

[54] Olivia Miller. 2019. This Sex Robot Can Breathe Using Her 'AI Chest Cavity': AI Robots. https://www.technowize.com/this-sex-robot-can-breathe-usingher-ai-chest-cavity/

[55] Mimic News. 2020. My First Day as a Robot Sex Worker. https://mimicnews.com/my-first-day-as-a-robot-sex-worker

[56] Janice M. Morse, 2008. Confusing categories and themes. Qualitative Health Research 18, 6 (Jun, 2008), 727-728. DOI https://doi.org/10.1177\%2F1049732308314930

[57] Glynis H. Murphy and Ali L. I. O’Callaghan, 2004. Capacity of adults with intellectual disabilities to consent to sexual relationships. Psychological Medicine 34, 7 (Oct, 2004), 1347-1357. DOI: https://doi.org/10.1017/S0033291704001941

[58] Maciej Musiał, 2019. Robots enchanting humans. In Enchanting Robots: Intimacy, Magic, and Technology, Maciej Musiał (Eds.). Springer, 11-62. DOI: https://doi.org/10.1007/978-3-030-12579-0_2.

[59] Hoang Nguyen. 2020. In 2020, both men and women are more likely to consider having sex with a robot. YouGov. https://today.yougov.com/topics/science/articles-reports/2020/03/19/2020both-men-and-women-are-more-likely-consider-h

[60] Allan Noonan and Miriam T. Gomez, 2011. Who's Missing? Awareness of Lesbian, Gay, Bisexual and Transgender People with Intellectual Disability. Sex and Disabil 29, (Aug, 2010), 175-180. DOI: https://doi.org/10.1007/s11195010-9175-3

[61] Chuka Nwanazia. 2018. Sex Care in The Netherlands - Helping the Disabled Find Intimacy. Dutch Review. https://dutchreview.com/culture/lovedating/sex-care-in-the-netherlands-helping-the-disabled-find-intimacy/

[62] Sven Nyholm and Lily E. Frank, 2019. It Loves Me, It Loves Me Not: Is It Morally Problematic to Design Sex Robots that Appear to Love Their Owners?. Techne: Research in Philosophy and Technology 23, 3 (Dec, 2019), 402-424. DOI: https://doi.org/10.5840/techne2019122110

[63] Satu Pekkarinen, Lea Hennalaa, Outi Tuiskua, Christine Gustafsson, RoseMarie Johansson-Pajala, Kirsten Thommes, Julia A. Hoppe, and Helinä Melkas, 2020. Embedding care robots into society and practice: Sociotechnical considerations. Futures 122, (Jun, 2020), 102593. DOI https://doi.org/10.1016/j.futures.2020.102593

[64] Brea L. Perry and Eric R. Wright, 2006. The sexual partnerships of people with serious mental illness. Journal of Sex Research 43, 2 (May, 2006), 174181. DOI: https://doi.org/10.1080/00224490609552312

[65] Adam Poulsen and Oliver K. Burmeister, 2019. Overcoming carer shortages with care robots: Dynamic value trade-offs in run-time. Australasian fournal of Information Systems, 23, 1-18. DOI: https://doi.org/10.3127/ajis.v23i0.1688

[66] Adam Poulsen, Oliver K. Burmeister, and David Tien. 2018. A new design approach and framework for elderly care robots. In Proceedings of Australasian Conference on Information Systems. 1-12. http://www.acis2018.org/wpcontent/uploads/2018/11/ACIS2018_paper_162.pdf

[67] Adam Poulsen, Ivan Skaines, Suzanne McLaren and Oliver K. Burmeister, 2020. Value Sensing Robots: The Older LGBTIQ+ Community. In Societal Challenges in the Smart Society, Mario Arias-Oliva, Jorge P. Borondo, Kiyoshi Murata, and Ana M, Lara (Eds.). Universidad de La Rioja, 275-287. https://dialnet.unirioja.es/servlet/libro? codigo $=769585$

[68] Chris Quinn and Graeme Browne, 2009. Sexuality of people living with a mental illness: A collaborative challenge for mental health nurses. International Journal of Mental Health Nursing 18, 3 (May, 2009), 195-203. DOI: https://doi.org/10.1111/j.1447-0349.2009.00598.x

[69] Kathleen Richardson, 2015. The asymmetrical 'relationship': parallels between prostitution and the development of sex robots. ACM SIGCAS 
Computers and Society 45, 3 (Jun, 2016), 290-293. DOI: https://doi.org/10.1145/2874239.2874281

[70] Kathleen Richardson, 2016. Sex robot matters: slavery, the prostituted, and the rights of machines. IEEE Technology and Society Magazine 35, 2 (Jun, 2016), 46-53. DOI: https://doi.org/10.1109/MTS.2016.2554421

[71] Carlotta Rigotti. 2019. Sex robots: a human rights discourse? Open Global Rights. https://www.openglobalrights.org/sex-robots-a-human-rightsdiscourse/

[72] Jennifer Robertson, 2010. Gendering humanoid robots: Robo-sexism in Japan. Body \& Society 16, 2 (Jul, 2010), 1-36. DOI:

https://doi.org/10.1177/1357034X10364767

[73] Stefania Roussel. 2013. Seeking Sexual Surrogates. Video. The New York Times. Retrieved from

https://www.nytimes.com/video/world/europe/100000002304193/seekingsexual-surrogates.html

[74] Lamber Royakkers and Rinie van Est. 2015. Just Ordinary Robots: Automation from Love to War. CRC Press.

[75] Matthias Scheutz, 2014. The inherent dangers of unidirectional emotional bonds between humans and social robots. In Robot Ethics: The Ethical and Social Implications of Robotics, Patrick Lin, Keith Abney, and George Bekey (Eds.). MIT Press, 205-221.

[76] Matthias Scheutz and Thomas Arnold, 2016. Are we ready for sex robots? In Proceedings of 11th ACM/IEEE International Conference on Human-Robot Interaction. 351-358. DOI: http://dx.doi.org/10.1109/HRI.2016.7451772

[77] Matthias Scheutz and Thomas Arnold, 2017. Intimacy, Bonding, and Sex Robots: Examining Empirical Results and Exploring Ethical Ramifications. In Robot Sex: Social and Ethical Implications, John Danaher and Neil McArthur (Eds.). DOI: http://dx.doi.org/10.7551/mitpress/9780262036689.003.0013

[78] Laurent Servais, 2006. Sexual health care in persons with intellectual disabilities. Mental Retardation and Developmental Disabilities Research Reviews, 12, 1 (Jan, 2006), 48-56. DOI: https://doi.org/10.1002/mrdd.20093

[79] Amanda Sharkey and Noel Sharkey, 2010. Granny and the robots: ethical issues in robot care for the elderly. Ethics and Information Technology 14, 1 (Jul, 2010), 27-40. DOI: https://doi.org/10.1007/s10676-010-9234-6

[80] Noel Sharkey, Aimee van Wynsberghe, Scott Robbins, and Eleanor Hancock, 2017. Our sexual future with robots: A Foundation for Responsible Robotics consultation report. https://responsible-robotics-myxf6pn3xr.netdnassl.com/wp-content/uploads/2017/11/FRR-Consultation-Report-Our-SexualFuture-with-robots-.pdf

[81] Russell P. Shuttleworth, 2000. The search for sexual intimacy for men with cerebral palsy. Sexuality and Disability 18, 4 (Dec, 2000), 263-282. DOI: https://doi.org/10.1023/A:1005646327321

[82] Robert Sparrow, 2017. Robots, rape, and representation. International fournal of Social Robotics 9, (Jun, 2017), 465-477. DOI: https://doi.org/10.1007/s12369017-0413-z

[83] Robert Sparrow, 2021. Sex robot fantasies. Journal of Medical Ethics 47, 1 (Oct, 2020), 33-34. DOI: https://doi.org/10.1136/medethics-2020-106932.

[84] Special Eurobarometer 382: Public Attitudes Towards Robots. 2012. http://ec.europa.eu/commfrontoffice/publicopinion/archives/ebs/ebs_382_en. pdf

[85] Bernd C. Stahl, Neil McBride, Kutoma Wakunuma, and Catherine Flick, 2014. The empathic care robot: A prototype of responsible research and innovation. Technol. Forecast. Soc. Change 84, (Aug, 2013), 74-85. DOI: https://doi.org/10.1016/j.techfore.2013.08.001

[86] Jack Stilgoe, Richard Owen, and Phil Macnaghten, 2013. Developing a framework for responsible innovation. Res. Policy 42, 9 (May, 2013), 15681580. DOI: https://doi.org/10.1016/j.respol.2013.05.008

[87] Norman M. Su, Amanda Lazar, Jeffrey Bardzell, and Shaowen Bardzell, 2019. Of Dolls and Men: Anticipating Sexual Intimacy with Robots. ACM Trans. Comput.-Hum. Interact 26, 3 (May, 2019), 1-35. DOI https://doi.org/10.1145/3301422

[88] John P. Sullins, 2012. Robots, love, and sex: the ethics of building a love machine. IEEE Transactions on Affective Computing 3, 4, 398-409. DOI: https://doi.org/10.1109/T-AFFC.2012.31
[89] Jessica M. Szczuka and Nicole C. Krämer, 2016. Influences on the intention to buy a sex robot. In Love and Sex with Robots, Adrian D. Cheok, Kate Devlin, and David Levy (Eds.). Springer, 72-83. DOI: https://doi.org/10.1007\%2F978-3319-57738-8_7

[90] Jessica M. Szczuka and Nicole C. Krämer, 2017. Not only the lonely-how men explicitly and implicitly evaluate the attractiveness of sex robots in comparison to the attractiveness of women, and personal characteristics influencing this evaluation. Multimodal Technologies and Interaction 1, 1 (Feb, 2017), 1-18. DOI: https://doi.org/10.3390/mti1010003

[91] Marleen Temmerman, Rajat Khosla, and Lale Say, 2014. Sexual and reproductive health and rights: a global development, health, and human rights priority. The Lancet 384, 9941 (Jul, 2014), 30-31. DOI https://doi.org/10.1016/S0140-6736(14)61190-9

[92] Mitchell S. Tepper, 2000. Sexuality and disability: The missing discourse of pleasure. Sexuality and disability 18, 4 (Dec, 2000), 283-290. DOI: https://doi.org/10.1023/A:1005698311392

[93] Carme Torras, 2019. Assistive robotics: Research challenges and ethics education initiatives. International fournal of Applied Ethics 30, 1-15. DOI https://doi.org/10.13039/501100003329

[94] United Nations. 1993. Standard Rules on the Equalization of Opportunities for Persons with Disabilities. https://www.un.org/disabilities/documents/gadocs/standardrules.pdf

[95] United Nations. 2007. Convention on the Rights of Persons with Disabilities and Optional Protocol. https://www.un.org/disabilities/documents/convention/convoptprot-e.pdf

[96] Kristi Urry and Anna Chur-Hansen, 2020. Who decides when people can have sex? Australian mental health clinicians' perceptions of sexuality and autonomy. Fournal of health psychology 25, 13-14 (Jul, 2018), 2188-2199. DOI: https://doi.org/10.1177/1359105318790026

[97] Shannon Vallor, 2011. Carebots and caregivers: Sustaining the ethical ideal of care in the twenty-first century. Philosophy \& Technology 24, 3 (Mar, 2011), 251-268. DOI: https://doi.org/10.1007/s13347-011-0015-x

[98] Janna van Grunsven and Aimee van Wynsberghe, 2019. A Semblance of Aliveness: How the Peculiar Embodiment of Sex Robots will Matter. Techne: Research in Philosophy and Technology 23, 3, 290-317. DOI: https://doi.org/10.5840/techne20191125105

[99] Aimee van Wynsberghe, 2013. Designing robots for care: Care centered value-sensitive design. Science and Engineering Ethics 19, 2 (Jan, 2012), 407433. DOI: https://doi.org/10.1007/s11948-011-9343-6

[100] Cathy Vaughan, Jerome Zayas, Alexandra Devine, Liz Gill-Atkinson, Manjula Marella, Joy Garcia, ... Ma J. Marco, 2015. W-DARE: a three-year program of participatory action research to improve the sexual and reproductive health of women with disabilities in the Philippines. BMC Public Health 15, 984 (Sep 2015), 1-7. DOI: https://dx.doi.org/10.1186\%2Fs12889-015-2308-y

[101] Jutta Weber, 2005. Helpless machines and true loving care givers: a feminist critique of recent trends in human-robot interaction. Journal of Information, Communication, and Ethics in Society 3, 4 (Nov, 2005), 209-218. DOI: https://doi.org/10.1108/14779960580000274

[102] Nathan J. Wilson, Jemima Macdonald, Brenda Hayman, Alexandra M. Bright, Patsie Frawley, and Gisselle Gallego, 2018. A narrative review of the literature about people with intellectual disability who identify as lesbian, gay, bisexual, transgender, intersex or questioning. Fournal of Intellectual Disabilities 22, 2 (Dec, 2016), 171-196. DOI: https://doi.org/10.1177\%2F1744629516682681

[103] World Health Organization. 2015. Sexual Health, Human Rights and the Law Report.

https://apps.who.int/iris/bitstream/handle/10665/175556/9789241564984_eng. pdf

[104] World Health Organization. 2019. Defining sexual health https://www.who.int/reproductivehealth/topics/sexual_health/sh_definitions /en/ 